\title{
Effect of Average Worker Size on Tunneling Behavior of Formosan Subterranean Termite Colonies
}

\author{
Cory E. Campora ${ }^{1}$ and J. Kenneth Grace ${ }^{1,2}$
}

Accepted May 4, 2004; revised July 15, 2004

The effect of a colony's average worker size on tunneling behavior of Coptotermes formosanus Shiraki (Isoptera: Rhinotermitidae) in laboratory foraging arenas was investigated. Large groups of foragers from four colonies were added to arenas and allowed to tunnel for a period of 22 days. Various aspects of the resulting tunnel galleries were analyzed using ANOVA and regression analysis. After the exclusion of one colony due to high mortality, the only parameters shown to differ significantly were tunnel width and tunnel segmentation. Larger workers tended to construct less segmented galleries with wider tunnels. Tunnel length was positively correlated to size on the first 2 days, but the relationship reversed by day 4. Tunneling on day 1 was positively correlated to the discovery of food items. Our results indicate that a foraging group's average worker size can affect tunnel pattern and that groups composed of larger workers are better tunnelers, but groups of smaller sized workers are able to make up the difference over time. Possible explanations for size-related variation in tunneling behavior are discussed.

KEY WORDS: Coptotermes formosanus; intercolony variation; tunneling behavior; subterranean termites.

\footnotetext{
${ }^{1}$ Department of Plant and Environmental Protection Sciences (PEPS), University of Hawaii at Manoa, 3050 Maile Way, Room 310, Honolulu, Hawaii 96822.

${ }^{2}$ To whom correspondence should be addressed. E-mail: kennethg@hawaii.edu.
} 


\section{INTRODUCTION}

Colonies of subterranean termites can display considerable variation in average worker size. Mean worker wet weights of the Formosan subterranean termite, Coptotermes formosanus Shiraki, have been reported from 2.05 (Cornelius and Osbrink, 2001) to $6.81 \mathrm{mg}$ (Grace et al., 1995). Differences in average worker size can occur between colonies in the same general habitat (Su and La Fage, 1984a), between colonies utilizing different hosts in a natural habitat (Waller, 1988), in the same colony according to season (Waller and LaFage, 1987), or in the same colony according to colony age (Grace et al., 1995).

Research on the division of labor in subterranean termite colonies has shown that large workers are more efficient at tunneling than smaller sized workers. Observing marked individuals of Reticulitermes santonensis De Feytaud, Garnier-Sillam (1983) found a link between the size or "stage" of a worker and digging activity, with older, larger stages digging more and at faster rates than younger, smaller stages. Similarly, Crosland et al. (1997) showed that large workers of Reticlitermes fukienensis Light tunneled approximately 10 times the distance of smaller sized workers. Having groups of smaller sized workers perform various foraging behaviors in the presence and absence of larger workers, it was further found that tunneling was the only behavior smaller workers could not adequately compensate for in the absence of larger workers. This finding prompted speculation that perhaps smaller workers utilize a different foraging pattern than larger workers to make up for their tunneling inefficiency due to size (Crosland and Traniello, 1997).

The current study investigates the effects of a foraging population's average worker size on its tunneling behavior. We explore this relationship in two-dimensional foraging arenas using large samples of termites from four different $C$. formosanus colonies covering a wide range of average worker size, with the primary objective to determine if colonies with larger workers are more efficient at foraging than those with smaller workers.

\section{MATERIALS AND METHODS}

\section{Arena Design}

Foraging trials were conducted in the laboratory using twodimensional arenas as described in previous work by Campora and Grace (2001). The arenas were designed such that two layers $(85 \times 85 \times 0.25 \mathrm{~cm}$ 


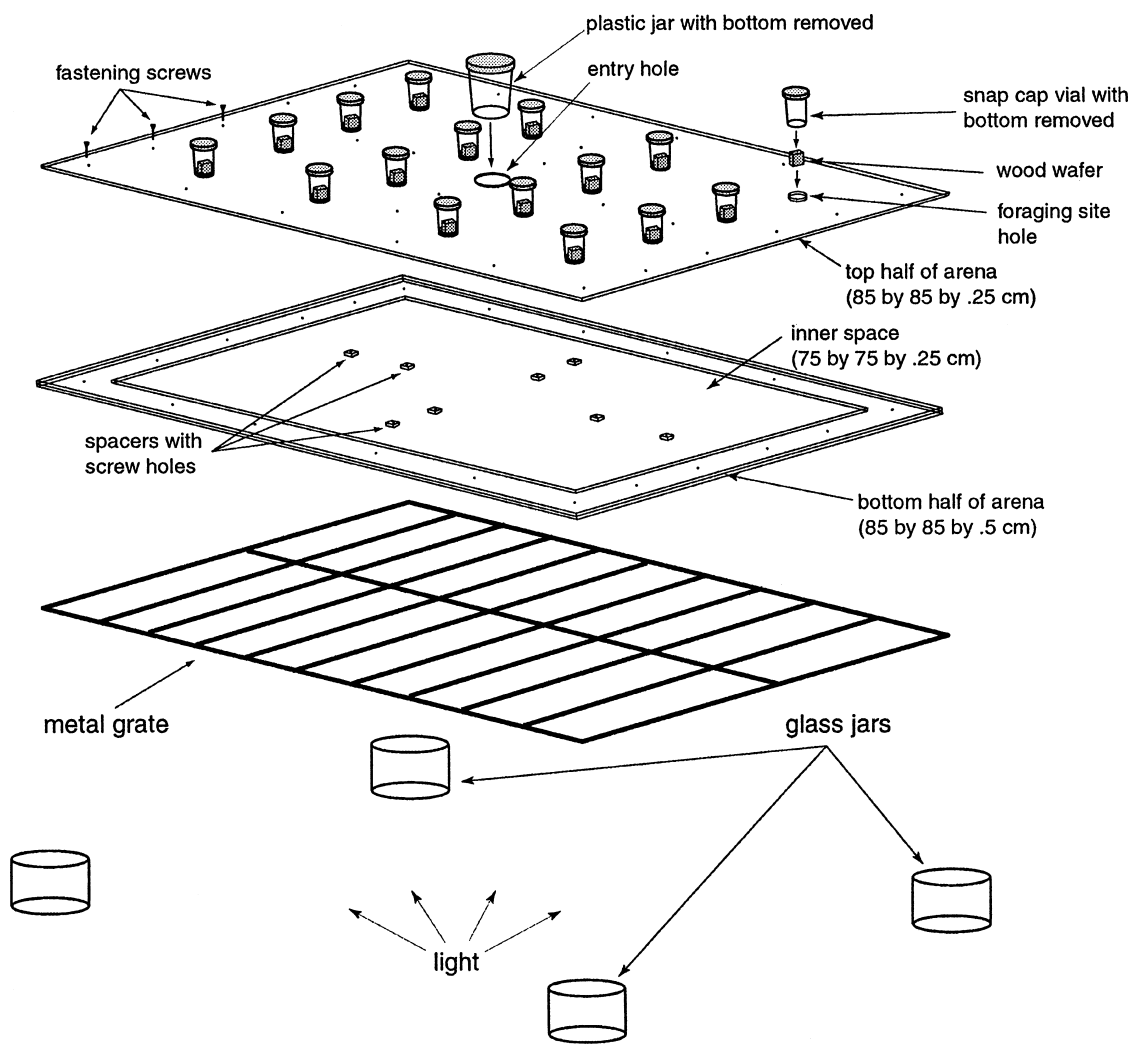

Fig. 1. Tunneling arena formed by fastening together two layers of clear acrylic. Wet sand between the layers serves as the tunneling substrate through which termites must dig to find food after they are added to the center jar.

and $85 \times 85 \times 0.50 \mathrm{~cm})$ of clear acrylic were fastened together with metal screws to create a space $(75 \times 75 \times 0.25 \mathrm{~cm})$ in the middle (Fig. 1). Eight small squares of acrylic with screw holes were affixed to the bottom layer to keep the space uniform after assembly. Silica sand (40-100 mesh (150-425 $\mu \mathrm{m}$ sieve), Fisher Scientific, Pittsburgh, PA) and distilled water (approximately $18 \%$ by weight) were added to the middle space to serve as the foraging substrate. The top layer of the arena had holes (3.1 $\mathrm{cm}$ in diameter) drilled every $20 \mathrm{~cm}$ in a grid pattern with one large hole $(8.2 \mathrm{~cm}$ in diameter) drilled in the center. Plastic vials (capacity 48 $\mathrm{mL}$ ) with the bottoms removed were inserted into the smaller holes to serve as foraging sites. Foraging sites contained preweighed wafers $(2.5$ $\times 2.0 \times 0.5 \mathrm{~cm}$ ) of Douglas fir, Pseudotsuga menziessii (Mirb.) Franco. 
A plastic jar (capacity $500 \mathrm{~mL}$ ) with the bottom removed was placed in the large center hole. This center site was where the termites were added into the arena and served as their point of entry into the tunneling substrate. Two 9-cm diameter discs of moistened filter paper were placed in the entry jar to provide surface area and an initial food source for the termites. Arenas rested on a metal grate supported by glass jars and were kept in a dark room. Backlighting from beneath arenas was achieved with florescent lighting, thus enabling tunnels to be photographed for computer analysis.

\section{Protocol}

Termites were collected from four different field sites and are referred to here (according to average worker size from largest to smallest) as Colonies I, II, III, and IV. Colony I was located in the central plateau region of Oahu at the Hawaii agricultural experiment station in Poamoho. Colony II was located on the University of Hawaii campus near Miller Hall. Colony III was located on the University of Hawaii campus near Gilmore Hall. Colony IV was located on the windward side of Oahu at a private residence in Kailua. There were a total of five foraging trials with one arena per colony in each trial. Treatment of the Kailua residence with a baiting system prevented Colony IV from being used in the final trial. Termites were extracted from their colonies, counted, weighed, and added to arenas within $24 \mathrm{~h}$. Fifteen hundred termites (90\% workers and 10\% soldiers) were added to each arena. Average worker biomass for each colony was determined by weighing 5 groups of 50 workers. Each foraging trial was conducted over a 22-day period. Digital photographs (D-600L Digital Camera, OLYMPUS, Melville, NY) were taken daily to monitor tunneling. At the end of each trial surviving termites were extracted, and the workers and soldiers were counted and preserved in $70 \%$ ethanol. All wood in the foraging sites and remaining filter paper in the initiation site were extracted, oven dried, and weighed. After all trials had been completed, 10 workers each were chosen at random from the preserved samples of termites for measurement of their head width. Heads were measured at the capsule's widest point, and an average width was obtained for each colony in four of the five tunneling trials (specimens were not available from the final trial). The arenas were housed in a facility with limited temperature control; therefore, temperature of the ambient environment fluctuated concurrently with the outside daily temperature. Temperatures inside the facility ranged from highs of 26 to $30^{\circ} \mathrm{C}$ in the late afternoon to lows of 20 to $24^{\circ} \mathrm{C}$ in the early morning. 


\section{Tunneling and Foraging Analysis}

ArcView 3.2 GIS software (ESRI Inc., Redlands, CA) was used to process images and digitize tunnels for volume, length, and width measurements. To calculate tunnel volume we adopted the method of Hedlund and Henderson (1999) and used a depth constant of $0.2 \mathrm{~cm}$ because we similarly observed that tunnels either were constructed along the top or bottom surface of the arena with a thin layer of sand on the other side. All tunnel segments within each gallery system were counted after the 22-day foraging period. Foraging sites were inspected at the end of each trial and sites discovered by termites were counted. Total consumption (wood and filter paper) per termite was calculated under the assumption of linear mortality using the equation $2(W 1-W 2) /(1350+N \mathrm{t})(\mathrm{Su}$ and La Fage, 1984b), where $W 1$ is the initial food weight, $W 2$ is the final food weight, and $N \mathrm{t}$ is the number of workers alive upon extraction at 22 days. We excluded biomass from the equation because of our interest in examining average worker wet weight as a predictive variable.

\section{Statistical Analysis}

The effects of colony source and date of foraging trial on worker wet weight, tunneling, foraging, and survivorship were examined by independent one way ANOVA tests using the general linear model procedure (Proc GLM) (SAS Institute, 1999). Significant differences between colonies or trials were explored using the Tukey highly significant difference (HSD) test with an alpha level of 0.05. Regression analysis (Proc REG) (SAS Institute, 1999) was used to evaluate the relationship between average worker wet weight and the experimental variables measured. Using the same procedure, the average worker wet weight of each colony was regressed against average head width, and the number of sites discovered on the first day of the trials was regressed against tunnel length.

\section{RESULTS}

Comparison of mean worker wet weights separated the colonies into two general size classes, with Colonies I and II containing significantly larger workers than Colonies III and IV $(F=33.47$, df $=4, P<0.0001)$ (Table I). Regression of worker weight on head capsule width confirmed that heavier workers had wider heads (Fig. 2). There were significant differences between colonies in total volume tunneled $(F=26.26, \mathrm{df}=4$, 


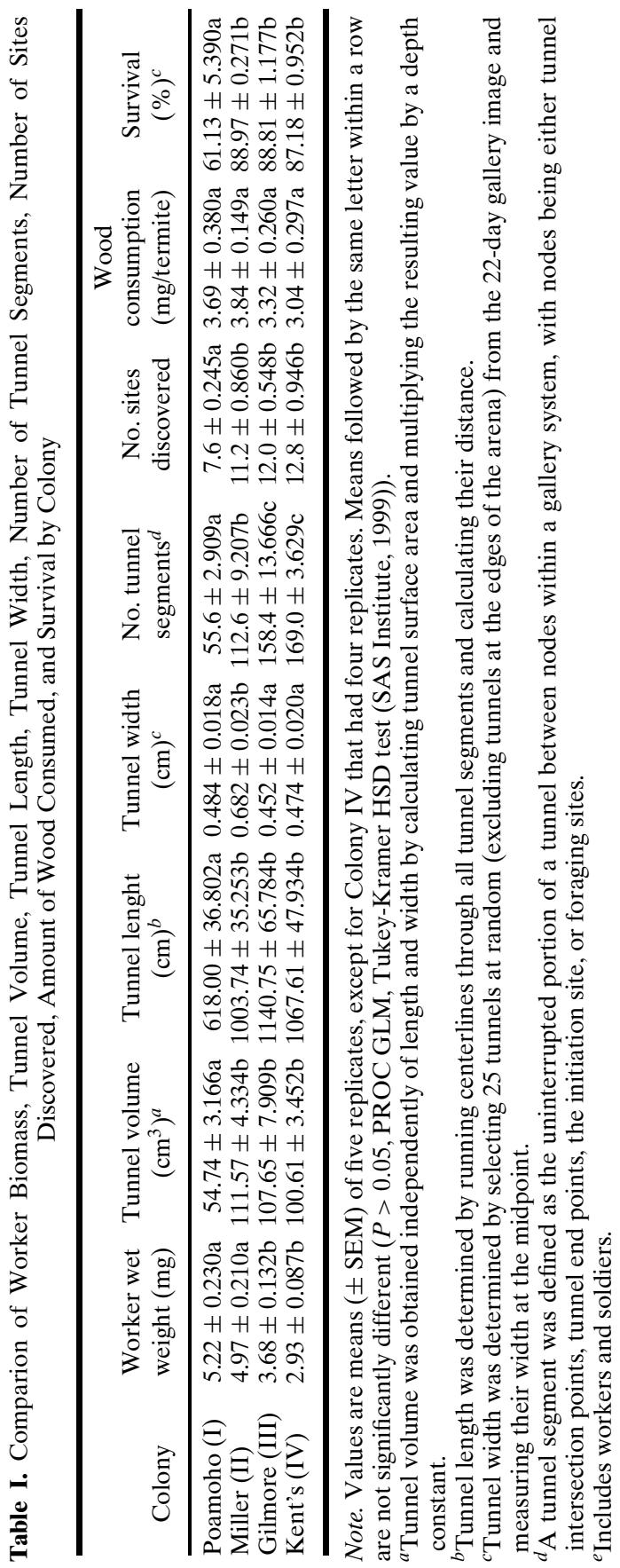




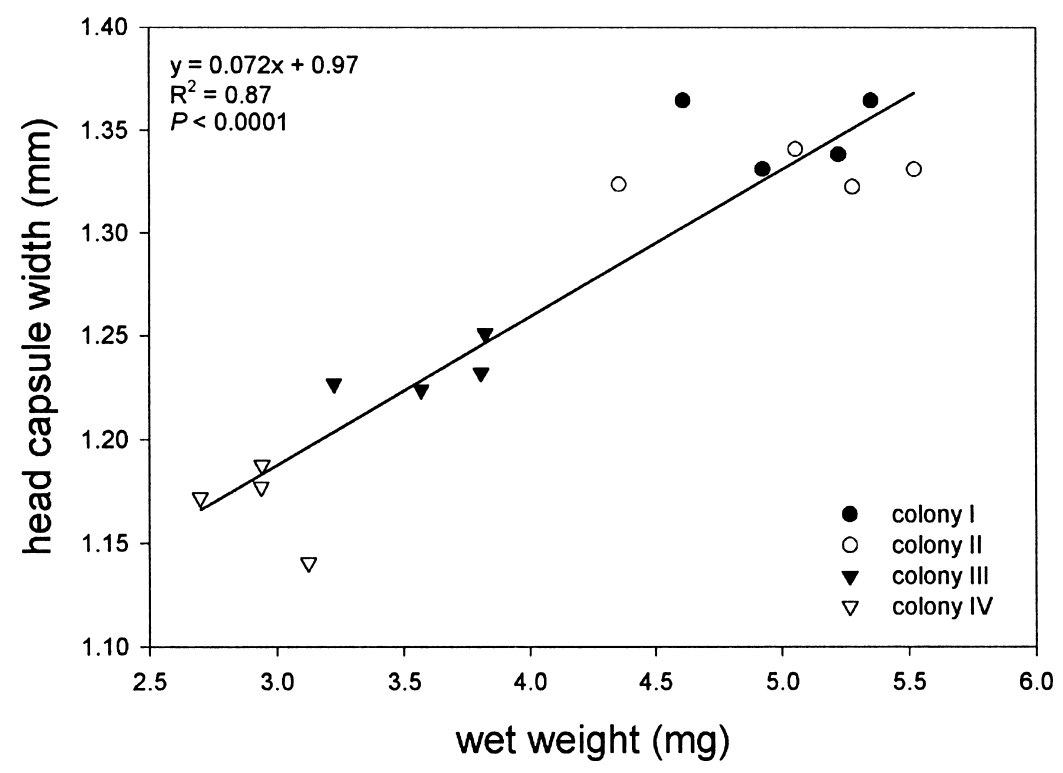

Fig. 2. Regression analysis of average wet weight against average head capsule width of termite workers from the four colonies used in the study.

$P<0.0001)$, total length tunneled $(F=24.25, \mathrm{df}=4, P<0.0001)$, tunnel width $(F=33.92, \mathrm{df}=4, P<0.0001)$, tunnel segmentation $(F=32.95$, $\mathrm{df}=4, P<0.0001)$, number of foraging sites discovered $(F=11.36, \mathrm{df}=$ $4, P=0.0004)$, and survival $(F=21.03, \mathrm{df}=4, P<0.0001)$. There was no difference in consumption between the four colonies $(F=1.52$, df $=4$, $P=0.2502$ ). Colony I accounted for most of the variation, tunneling significantly less in terms of volume and length, creating the fewest segments, and discovering fewer foraging sites than the other three colonies. This was likely due to the fact that it was also significantly weaker, displaying on average $61 \%$ survival compared to approximately $88 \%$ survival of the other colonies. Discounting Colony I due to high mortality, Colonies II, III, and IV differed only in tunnel width and segmentation. Colony II dug wider tunnels with fewer segments than Colonies III and IV. The date on which foraging trials were conducted was found to have no significant effect on any of the experimental variables.

Regression of average worker weight on tunnel volume, tunnel length, tunnel width, number of tunnel segments, number of sites discovered, and consumption was conducted without Colony I because of its higher mortality and consisted only of data from Colonies II, III, and IV. The only variables to show a significant relationship to worker weight were tunnel width 


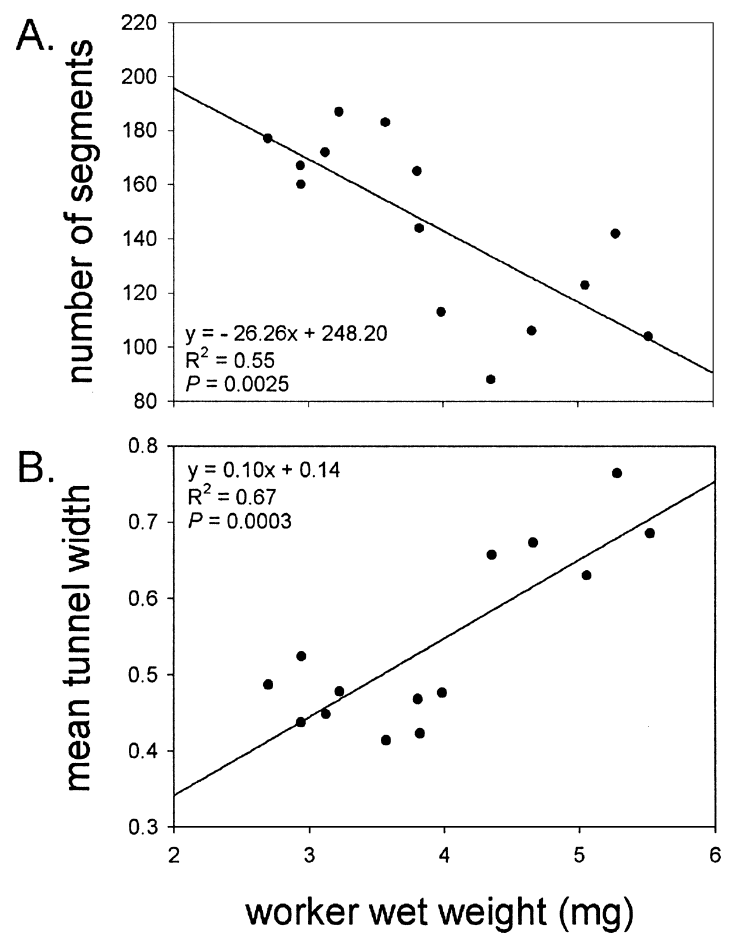

Fig. 3. Regression analyses of average worker wet weight against (A) the number of tunnel segments created and (B) the average width of tunnels created by Colonies II, III, and IV.

and number of tunnel segments. Average worker weight was negatively correlated to the number of tunnel segments (Fig. 3a) and positively correlated to tunnel width (Fig. 3b).

The average length tunneled by Colonies II, III, and IV on each day of the foraging trials is represented in Fig. 4. We used tunnel length for this analysis instead of volume to correct for differences in tunnel width between the colonies. While there were no differences in overall length, we did see significant differences during the early stages of gallery formation. On day 1, colony II tunneled significantly more than Colonies III and IV ( $F=13.01, \mathrm{df}=3, P=0.0013)$, and on day 2 Colonies II and III tunneled significantly longer than Colony IV $(F=4.16$, df $=3, P=0.0450)$. On day 12 Colony IV tunneled significantly more than Colonies II and III $(F=$ 6.52 , $\mathrm{df}=3, P=0.0136$ ). The length of tunnels constructed during each of the first 4 days of the 22-day foraging trials is regressed against worker weight in Fig. 5. On day 1 there was a strong positive relationship between 


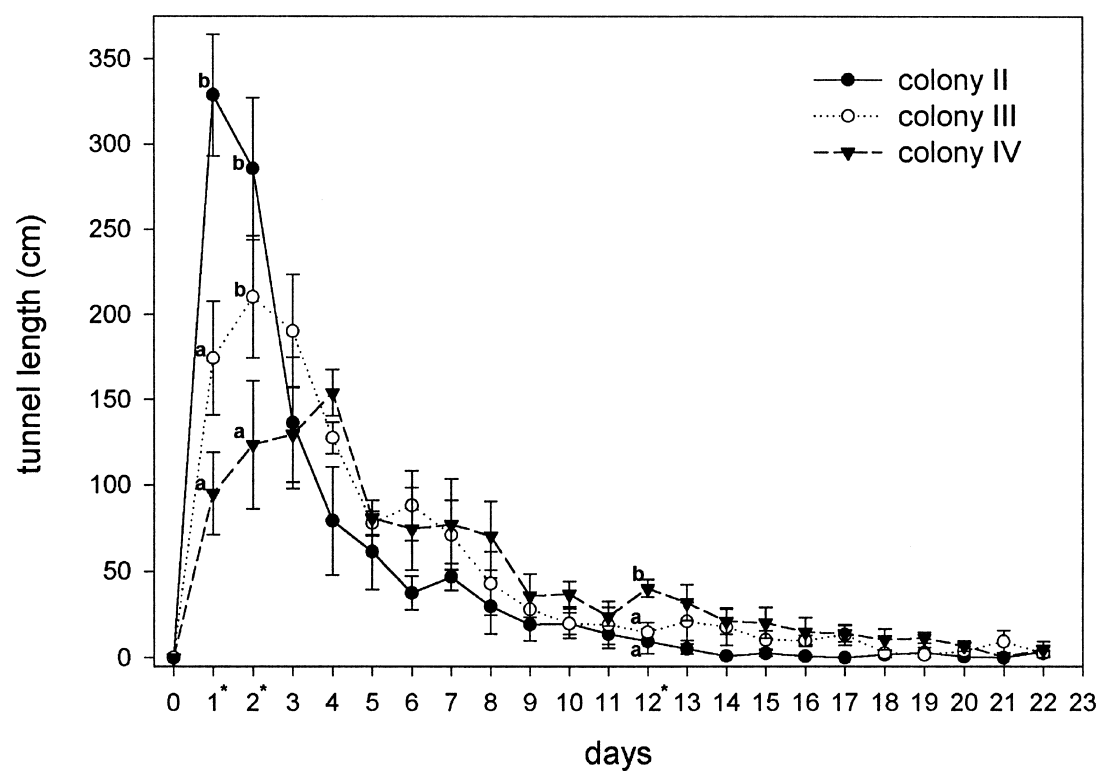

Fig. 4. Average length tunneled by Colonies II, III, and IV on each day of the foraging trials. Asterisk (*) indicates the days on which tunneling means varied significantly $(P>0.05$, PROC GLM, (SAS Institute, 1999)). Means followed by the same letter are not significantly different (Tukey-Kramer HSD test).

worker weight and tunnel length. The relationship persisted through day 2 , but was beginning to weaken. By day 3 tunneling showed no correlation to worker weight. On day 4 the relationship shifted and there was a negative correlation, with smaller sized workers tunneling more than the larger workers. There was a significant relationship between tunnel length and the number of sites discovered on day 1 (Fig. 6).

\section{DISCUSSION}

Excluding the weak termite colony involved in our study, we found evidence supporting the hypothesis that average worker size of a large foraging group has an effect on the group's tunneling efficiency, and, in at least two aspects (tunnel width and tunnel segmentation), has an effect on tunnel pattern. Our findings partly sustain research by Cornelius and Osbrink (2001) who demonstrated that after 21 days of tunneling, colonies of $C$. formosanus with greater average body weights created a larger tunneling area than 


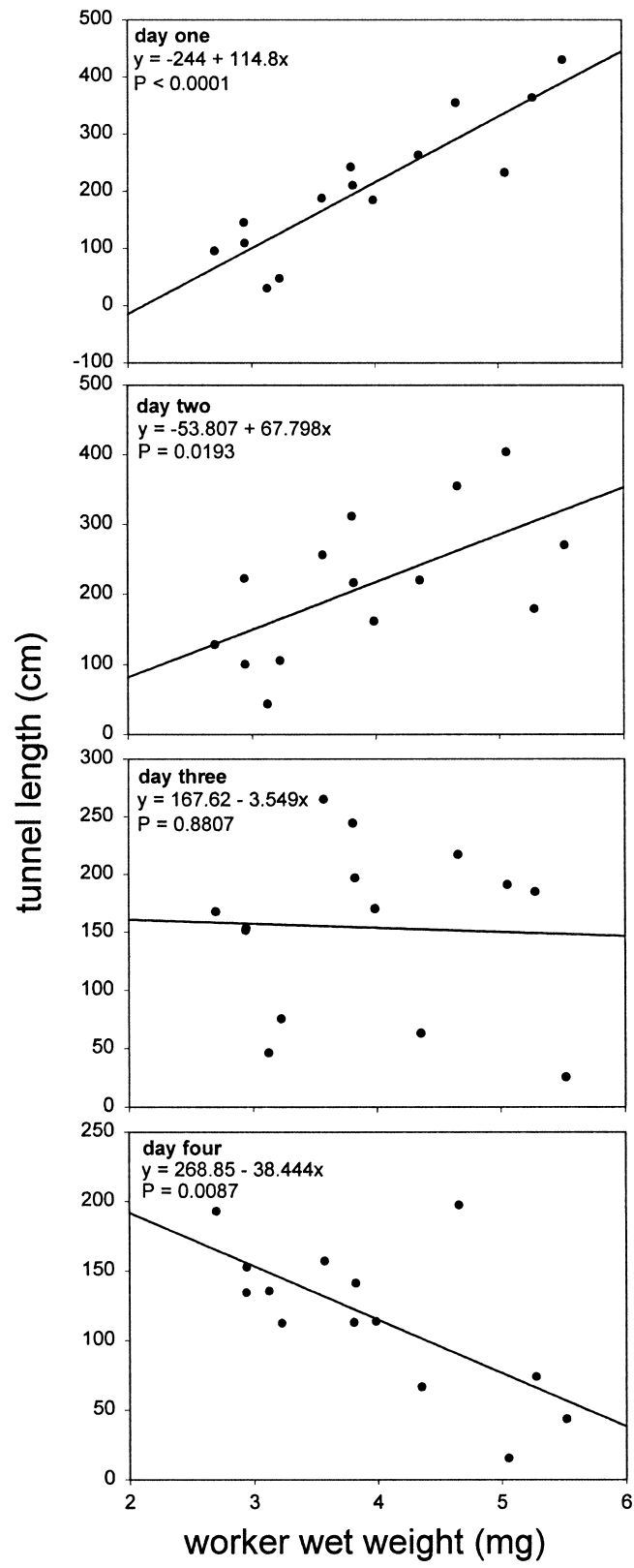

Fig. 5. Regression analysis of average worker wet weight against length tunneled by Colonies II, III, and IV on each of the first 4 days of foraging trials. 


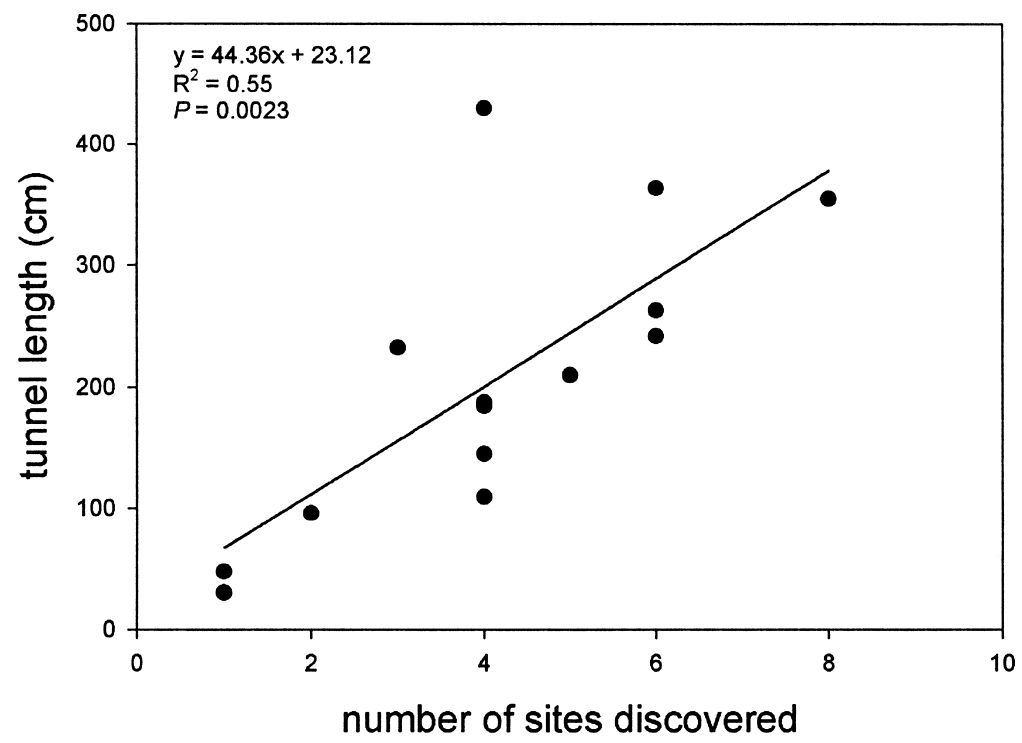

Fig. 6. Regression analysis of length tunneled on the first day of foraging trials against the number of foraging sites discovered on the first day by Colonies II, III, and IV.

colonies with lower average body weights. The size advantage in tunneling we observed was manifest during the initial period (first 2 days) of tunnel formation, and was not evident when comparing the final amount of tunneling. In fact, most of the tunneling by termites was done during the first week of the foraging trials. Initial rapid tunnel excavation tapering to limited tunneling activity has been reported by other researchers and was attributed to a lack of food stimulus within the foraging area (Hedlund and Henderson, 1999). In the experiment mentioned above, foragers began with varying amounts of food and were allowed to tunnel outward into an area where no further food items existed. Our foraging trials were designed such that termites began with only a small amount of food (filter paper) and were required to tunnel outward to discover additional food items arranged uniformly throughout the arena. We know from Fig. 5 that healthy foraging groups consisting of larger individuals tended to tunnel more on day 1. Additionally, Fig. 6 shows that healthy foraging groups tunneling more on the first day tended to discover more food items. Integrating this information provides an explanation for the shift in slope of the regression lines over time in Fig. 5. We can assume that as more food is discovered the stimulus to search for additional food resources decreases. Therefore, because 
the foraging groups with larger termites tunneled more in the beginning and discovered more wood earlier in the trials, their tunneling activity tended to peak sooner. Groups with smaller sized foragers found the same amount of food items by the end of the trials, but they were slower to discover the food items, and consequently their tunneling activities were more drawn out.

One proposed explanation for a size advantage in tunneling is that larger termites are better tunnelers because they have bigger mouthparts for transporting particles of substrate (Crosland and Traniello, 1997). Our measure of worker size, wet weight, did not directly provide information relative to mouthparts, but the result of the regression analysis of wet weight on head capsule width indicated that termites with greater biomass did indeed have larger heads. Actual mouthparts were not measured, and we must therefore presume that mouthpart size was positively associated with head capsule size. Large size probably provides some physical advantage in the mechanics of tunneling, but this benefit is more likely related to tunneling rate and not attributable to tunnel width or segmentation. Tunnel width is more a function of the number of termites focusing on a specific tunnel during its formation rather than the size of the mandibles relocating the particles of sand. Tunnel widths reported from this study are approximately one-third of tunnel widths listed for $C$. formosanus by Puche and Su (2001), who observed C. formosanus widening its tunnels after release into the foraging area. In general we did not observe workers widening existing tunnels. Additional areas of sand were excavated at the bases of some tunnels leaving the center initiation site, but because we measured segments at their midpoints, these areas did not affect our width measurements.

Alternatively, McMahan (1979) suggested that in comparison to smaller workers, larger termite workers possess larger sternal glands and produce higher pheromone titers which elicit stronger recruitment responses from other foraging individuals. This theory implies the following points: (1) Sternal gland size increases throughout the development of the worker; (2) Sternal gland size is directly related to pheromone concentration; and (3) Recruitment response is concentration-dependent. While termite sternal glands have been shown to vary significantly in size between castes (Leuthold and Luscher, 1974; Traniello and Busher, 1985), there is little evidence of variation in gland size within a caste. Traniello and Busher (1985) reported a range of volumes for glands of the large worker caste (third instar) of Nasutitermes costalis (Holmgren), but it is not clear whether the variation in gland volume was correlated to body size. Regardless, they did demonstrate a significant correlation between gland volume and recruitment activity within the third instar worker caste. 
Considering this explanation, it is therefore conceivable that the differences in tunnel pattern and tunnel construction we observed between the three healthy colonies were partially due to variation in recruitment response to different concentrations of pheromone deposited by foragers. Of the tunnel features we measured, only tunnel segmentation and tunnel width were significantly correlated to average forager size. Given a set number of foragers, greater recruitment responses could lead to higher numbers of termites focusing at fewer sites of tunnel excavation. Such a scenario might produce a search tunnel pattern composed of fewer yet larger tunnels. Oppositely, with a weaker recruitment response, termites may forage in a less concerted manner, resulting in more sites of tunnel excavation, but with less termites operating at each location. In theory, the latter situation would produce a diffuse, more segmented search tunnel pattern with narrower tunnels. The differences in tunneling rate between the colonies during the first 2 days of the foraging trials could also be attributed to pheromone concentration. Grace et al. (1988) found trail following activity and rate of locomotion in Reticulitermes hesperus Banks to be dependent on the amount of pheromone present.

We can only speculate why Colony I displayed significantly higher mortality. The manifestation of decreased vigor can be the result of a number of underlying factors, and it is not uncommon for variation in survival to occur between subterranean termite colonies during laboratory tests (Carter et al., 1972; Su and La Fage, 1984b; Lenz, 1985; Lenz and Dai, 1985; Thorne and Breisch, 2001). It is interesting to note however that our finding that colonies composed of larger workers tunneled more effectively is counterintuitive to certain ideas on the developmental cycle of subterranean termite colonies. In theory, average worker size is smaller in young colonies due to a greater proportion of younger individuals in the foraging population resulting from high rates of reproduction. As the colony enters a declining phase, reproduction rates are lower, and the demographics begin to shift toward a population consisting of older individuals with greater body mass. Early work in Japan cited a connection between colony age and vitality, stating that young colonies composed of smaller workers are stronger than older colonies consisting of larger sized workers (Shimizu, 1962). Additional support for this explanation is given by Grace et al. (1995). Tracking the average worker biomass and foraging population estimates of a single colony for 16 years, they demonstrated a strong relationship between the increase in average worker size and the decrease in the size of the foraging population. Results from the current study suggest that a colony's foraging ability increases as its foraging population ages, however, there is an age threshold beyond which the foraging population begins to senesce and lose vigor. This would explain why Colony I in our study displayed the highest mortality and 
tunneled the least compared to the other colonies even though it consisted of the largest workers. In a study using six different $C$. formosanus colonies, Cornelius and Osbrink (2001) also reported significantly higher mortality in the colony with the largest sized workers $(5.39 \pm 0.02 \mathrm{mg} /$ worker $)$.

Subterranean termite colonies exist in a complex environment that is subject to many factors that change over space and time. Factors such as environmental conditions, interactions with predators and pathogens, availability of food resources, and inherited genetic traits may all singly or in combination influence foraging activities. The influence of these factors can be difficult to assess in the subterranean environment, but through experimentation in the laboratory it is possible to examine their affects individually. We found that the average size of workers within a colony of $C$. formosanus is at least one factor that affects tunnel width, tunnel segmentation, and tunneling rate. Unfortunately, due to the exclusion of one colony because of high mortality, this relationship was established using only three colonies. Tunneling comparisons between a greater number of colonies covering a broad range of average worker sizes would be ideal. Nonetheless, while the causes may not be entirely apparent, it is clear that differences in tunneling occur between Formosan subterranean termite colonies. Understanding the causes for these differences could aid in the control of subterranean termite infestations by tailoring strategies to the specific foraging behaviors of individual colonies.

\section{AKNOWLEDGMENTS}

The authors express their gratitude to Carrie Tome, Robert Oshiro, Destiny St. Laurent, Takashi Brown, and Grace Lee for their assistance in termite collection and counting. We also thank Dr Julian Yates for his technical assistance and J. C. Plastics of Honolulu, HI for help in construction of foraging arenas. Financial support was provided by McIntire-Stennis funding, and by USDA-ARS Specific Cooperative Agreement 58-6615-9-018. This is Journal Series No. 4679 of the College of Tropical Agriculture and Human Resources.

\section{REFERENCES}

Campora, C. E., and Grace, J. K. (2001). Tunnel orientation and search pattern sequence of the Formosan subterranean termite (Isoptera: Rhinotermitidae). J. Econ. Entomol. 94: 1193-1199.

Carter, F. L., Stringer, C. A., and Smythe, R. V. (1972). Survival of six colonies of Reticulitermes flavipes on unfavorable woods. Ann. Entomol. Soc. Am. 65: 984-985. 
Cornelius, M. L., and Osbrink, W. L. A. (2001). Tunneling behavior, foraging tenacity, and wood consumption rates of Formosan and Eastern subterranean termites (Isoptera: Rhinotermitidae) in laboratory bioassays. Sociobiology 37: 79-94.

Crosland, M. W. J., Lok, C. M., Wong, T. C., Shakarad, M., and Traniello, J. F. A. (1997). Division of labour in a lower termite: The majority of tasks are performed by older workers. Anim. Behav. 54: 999-1012.

Crosland, M. W. J., and Traniello, J. F. A. (1997). Behavioral plasticity in division of labor in the lower termite Reticulitermes fukiensis. Naturwissenshaften 84: 208-211.

Garnier-Sillam, E. (1983). Le polyethisme chez Reticulitermes lucifigus santonensis (Isoptera Rhinotermitidae). Insectes Soc. 30: 9-26.

Grace, J. K., Wood, D. L., and Frankie, G. W. (1988). Trail-following behavior of Reticulitermes hesperus Banks (Isoptera: Rhinotermitidae). J. Chem. Ecol. 14: 653-667.

Grace, J. K., Yamamoto, R. T., and Tamashiro, M. (1995). Relationship of individual worker mass and population decline in a Formosan subterranean termite colony (Isoptera: Rhinotermitidae). Environ. Entomol. 24: 1258-1262.

Hedlund, J. C., and Henderson, G. (1999). Effect of available food size on search tunnel formation by the Formosan subterranean termite (Isoptera: Rhinotermitidae). J. Econ. Entomol. 92: 610-616.

Lenz, M. (1985). Variability of vigour between colonies of Coptotermes acinaciformis (Froggat) (Isoptera: Rhinotermitidae) and its implications for laboratory experimentation. Bull. Entomol. Res. 75: 13-21.

Lenz, M., and Dai, Z. R. (1985). On the validity of using susceptible timbers as indicators of termite vigour in laboratory studies on the resistance of materials to termites. Mater. Org. 20: $99-108$.

Leuthold, R. H., and Luscher, M. (1974). An unusal caste polymorphism of the sternal gland and its trail pheromone production in the termite Trinervitermes bettonianus. Insectes Soc. 21: $335-342$.

McMahan, E. A. (1979). Temporal polyethism in termites. Sociobiology 4: 153-167.

Puche, H., and Su, N.-Y. (2001). Tunnel formation by Reticulitermes flavipes and Coptotermes formosanus (Isoptera: Rhinotermitidae) in response to wood in sand. J. Econ. Entomol. 94: $1398-1404$.

SAS Institute (1999). Software Release 8.02 TS02M0 for Windows, SAS Institute, Cary, NC.

Shimizu, K. (1962). Analytical studies on the vitality of colonies of the Formosan subterranean termite Coptotermes formosanus Shiraki. I. Analysis of the strength of vitality. Bull. Fac. Agric. Univ. Miyazaki 8: 106-110.

Su, N.-Y., and La Fage, J. P. (1984a). Differences in survival and feeding activity among colonies of the Formosan subterranean termite (Isoptera: Rhinotermitidae). Z. Angew. Entomol. 97: 134-138.

Su, N.-Y., and La Fage, J. P. (1984b). Comparison of laboratory methods for estimating wood consumption rates by Coptotermes formosanus (Isoptera: Rhinotermitidae). Ann. Entomol. Soc. Am. 77: 125-129.

Thorne, B. L., and Breisch, N. L. (2001). Effects of sublethal exposure to imidachloprid on subsequent behavior of subterranean termite Reticulitermes virginicus (Isoptera: Rhinotermitidae). J. Econ. Entomol. 94: 492-498.

Traniello, J. F. A., and Busher, C. (1985). Chemical regulation of polyethism during foraging in the neotropical termite Nasutitermes costalis. J. Chem. Ecol. 11: 319-331.

Waller, D. A. (1988). Size variation in Coptotermes formosanus Shiraki (Rhinotermitidae): Consequences of host use. Am. Midl. Nat. 119: 436-440.

Waller, D. A., and LaFage, J. P. (1987). Seasonal patterns in foraging groups of Coptotermes formosanus (Rhinotermitidae). Sociobiology 13: 173-181. 